\title{
Digestibilidade Aparente dos Nutrientes de Rações Contendo Diferentes Fontes de Fibra e Níveis de Amido com Coelhos em Crescimento ${ }^{1}$
}

\author{
Alex Martins Varela de Arruda ${ }^{2}$, Darci Clementino Lopes ${ }^{3}$, Walter Motta Ferreira ${ }^{4}$, Horacio \\ Santiago Rostagno ${ }^{3}$, Augusto César de Queiroz ${ }^{3}$, Elzânia Sales Pereira ${ }^{2}$, Luiz Fernando \\ Teixeira Albino ${ }^{3}$, José Francisco da Silva ${ }^{3}$
}

\begin{abstract}
RESUMO - O objetivo do presente estudo foi avaliar a digestibilidade aparente dos nutrientes com coelhos em crescimento alimentados com rações contendo diferentes níveis de amido ( 22 a 32\% em média) mediante a inclusão de milho grão e diferentes fontes de fibra (feno de alfafa ou casca de soja), em esquema fatorial 2x2. As rações foram peletizadas e fornecidas a 64 coelhos da raça Nova Zelândia Branco (16 repetições por tratamento), desmamados aos 34 dias, alojados individualmente em gaiolas de metabolismo e distribuídos em delineamento inteiramente casualizado. Não foram observados efeitos significativos para a interação entre fontes de fibra e níveis de amido. A melhor digestibilidade dos nutrientes foi observada com as rações contendo maior nível de amido (73,56\%MS, $74,30 \% \mathrm{MO}, 71,51 \% \mathrm{~PB}, 63,89 \% \mathrm{~EB}, 95,08 \%$ amido, $45,87 \% \mathrm{FDN}, 37,78 \% \mathrm{FDA}, 55,57 \%$ hemicelulose, $39,86 \%$ celulose), exceto para fração lipídica. Por outro lado, melhor digestibilidade dos nutrientes foi observada com as rações contendo casca de soja (72,37\%MS, $73,06 \% \mathrm{MO}, 69,10 \% \mathrm{~PB}, 61,74 \% \mathrm{~EB}, 76,84 \% \mathrm{EE}, 95,10 \%$ amido, 47,00\%FDN, 38,42\%FDA, 55,51\% hemicelulose, 42,42\% celulose). Estes resultados sugerem que as rações com maiores níveis de amido ou com casca de soja podem ser utilizadas eficientemente pelos coelhos, respeitando-se as recomendações nutricionais.
\end{abstract}

Palavras-chave: casca de soja, coelhos, digestibilidade, feno de alfafa, milho grão, nutrição

\section{Nutrients Apparent Digestibility in Diets with Different Starch Levels and Fiber Source for Growing Rabbits}

\begin{abstract}
The objective of the present study was to evaluate the nutrients apparent digestibilities in growing rabbits fed diets with different starch levels ( 22 or $32 \%$ on average) by high or low inclusion of corn grain and different fiber sources (alfalfa hay or soybean hulls), in $2 \times 2$ factorial outline. The diets were pelleted and supplied to 64 New Zealand White rabbits ( 16 replicates per treatment), weaned at 34 days, housed individually in metabolism cages and allotted to a complete randomized design. Significant effects were not observed for the interaction between the starch levels and the fiber sources. The best digestibility was observed with high starch diets ( $73.56 \% \mathrm{DM}$, 74.30\%OM, 71.51\%CP, 63.89\%GE, 95.08\% starch, 45.87\%NDF, 37.78\%ADF, 55.57\% hemicellulose, 39.86\%cellulose), except for lipid fraction. On the other hand, the best digestibility of nutrients was observed with the diets containing with soybean hulls (72.37\%DM, 73.06\%OM, 69.10\% CP, 61.74\%GE, 76.84\%EE, 95.10\% starch, 47.00\%NDF, 38.42\%ADF, 55.51\% hemicellulose, $42.42 \%$ cellulose). These results suggest that diets with high starch levels or soybean hulls can be used efficiently by rabbits, maintaining the nutritional recommendations.
\end{abstract}

Key Words: alfalfa hay, corn grain, digestibility, nutrition, rabbits, soybean hulls

\section{Introdução}

A composição química é o ponto de partida para se determinar o valor nutritivo dos alimentos, mas sua real utilização depende da disponibilidade dos nutrientes para o animal, uma característica mensurada e expressa em termos de coeficientes de digestibilidade. No caso dos coelhos, em função do seu hábito alimentar e da natureza evolutiva, são considerados animais não ruminantes herbívoros de ceco funcional e praticantes de cecotrofia, particularidades do processo digestivo que direcionam as pesquisas na área da nutrição.

Entre os estudos realizados, constatou-se que, apesar destas características, a necessidade de fibra dietética prioriza a manutenção e o equilíbrio da fisiologia digestiva por intermédio da velocidade de trânsito da digesta, impondo limitações no aproveitamento de alimentos ou rações completas, além de influenciar a digestão e absorção de outros nutrientes

\footnotetext{
${ }^{1}$ Parte da tese de Doutorado do primeiro autor, financiado pela UFV e FAPEMIG.

${ }^{2}$ Professor do curso de Zootecnia da UNIOESTE, Mal. Cândido Rondon - PR. E.mail: amvarela39@hotmail.com

3 Professor do curso de Zootecnia da UFV, Viçosa - MG.

4 Professor do curso de Veterinária da UFMG, Belo Horizonte - MG.
} 
(Cheeke, 1987; De Blas, 1989). Os efeitos dos níveis de fibra sobre o processo digestivo de coelhos em crescimento sugerem um efeito protetor contra distúrbios digestivos, sendo recomendados níveis mínimos de $12 \%$ de fibra bruta ou $17 \%$ de fibra em detergente ácido para evitar hiperfermentação e desequilíbrio osmótico intestinal que gerem diarréias fatais (De Blas \& Wiseman, 1998). No entanto, não somente a quantidade de fração fibrosa da dieta, mas também a qualidade ou fracionamento dos constituintes da parede celular vegetal devem ser considerados no balanceamento de rações, pois alimentos volumosos de alta degradabilidade ou ricos em substâncias pécticas podem levar a disbioses na microflora cecal (Santomá et al., 1993; Gidenne, 1996).

Por outro lado, a inclusão de cereais na alimentação de coelhos em crescimento também impõe limitações no balanceamento de rações completas, especialmente a fração amilácea, visto que atividade enzimática específica para digestão desta pelo animal aumenta com a idade. A capacidade digestiva de coelhos pós-desmame não se realiza adequadamente, sendo necessário ultrapassar 8 semanas de idade para atingir digestibilidade amilásica eficiente (Cheeke, 1995). Assim, a relação amido:fibra nas rações tornou-se fator de investigação cada vez mais constante, visto que o fluxo excessivo de amido indigerido para o ceco-cólon propicia alterações significativas no padrão fermentativo e equilíbrio osmótico, prevalência de bactérias patogênicas subdominantes, causando diarréias e enterotoxemias fatais em coelhos (Cheeke \& Patton, 1980; Morisse, 1986; De Blas, 1991; Gidenne, 1996; Arruda et.al., 2000).

Diante do exposto, mínimo nível de alimentos fibrosos e máxima inclusão de cereais são permissíveis, diferenciando esta espécie com relação ao balanceamento dietético e à eficiência no aproveitamento da energia. Muitas pesquisas têm procurado avaliar a suplementação lipídica em rações para coelhos em crescimento, pois, ao se considerar a relação inversa entre quantidade de fibra e nível de energia, uma amplitude de 3 a $9 \%$ de adição óleo na dieta, dependendo da fonte, tem proporcionado bons índices produtivos e satisfatórios coeficientes de digestibilidade dos nutrientes (Ferreira, 1989; Lebas, 1992; Lebas, 1999).

Assim, o conhecimento dos fatores ligados aos animais e aos alimentos, que influenciam a utilização de nutrientes, torna-se importante para evitar possíveis inadimplências nas formulações de rações, as quais prejudicariam a obtenção de bons índices zootécnicos e manutenção da sanidade dos animais. Neste contexto, o presente estudo foi conduzido com o objetivo de avaliar a digestibilidade aparente dos nutrientes de rações contendo diferentes fontes de fibra e níveis de amido para coelhos da raça Nova Zelândia Branco em fase de crescimento.

\section{Material e Métodos}

O experimento foi conduzido no setor de Cunicultura, do Departamento de Zootecnia, do Centro de Ciências Agrárias, da Universidade Federal de Viçosa.

Foram utilizados 64 coelhos da raça Nova Zelândia Branco, de ambos os sexos, desmamados em torno dos 34 dias de idade, com cerca de $700 \mathrm{~g}$ de peso vivo, alojados individualmente em gaiolas de metabolismo de arame galvanizado, providas de bebedouros automáticos tipo chupeta e comedouro de chapa galvanizada semi-automático. Na parte inferior da gaiola ficaram as bandejas cobertas com tela de náilon que retinham as fezes e filtravam a urina, que era recolhida em recipiente próprio. As gaiolas dispostas em baterias estavam instaladas em um galpão de alvenaria com 6 metros de largura, pé-direito de 3 metros, com piso cimentado e cobertura de telha de amianto.

Para avaliar os efeitos das rações sobre a digestibilidade aparente dos nutrientes, os animais foram uniformizados com base no peso vivo e distribuídos aleatoriamente aos tratamentos, seguindo um delineamento inteiramente casualizado em esquema fatorial $2 \times 2$, resultantes de dois níveis de amido a partir da inclusão de milho grão ( 22 e $32 \%$ de amido em média) e duas fontes de fibra (feno de alfafa ou casca de soja) ambas associadas com sabugo de milho.

As rações experimentais foram elaboradas para atender as exigências nutricionais dos coelhos em crescimento segundo o INRA (1984) e Lebas et al. (1986), de forma a serem isoprotéicas e isocalóricas, tendo sido ainda peletizadas. A formulação e composição química das rações experimentais encontram-se nas Tabelas 1 e 2 , respectivamente.

O experimento teve duração de 24 dias ( 34 aos 58 dias de idade), sendo subdividido em oito dias para o período de adaptação e quatro dias para o período de coleta, em cada um dos quatro grupos de 16 animais, havendo sobreposição de períodos para realização do estudo durante o período crítico ao excesso de amido dietético ( 34 a 46 dias, 38 a 50 dias, 42 a 54 dias e 46 a 58 dias de idade). A quantidade de ração

R. Bras. Zootec., v.31, n.3, p.1166-1175, 2002 
Tabela 1 - Composição percentual das rações experimentais

Table 1 - Percent composition of the experimental diets

Tratamentos dietéticos

Dietary treatments

\begin{tabular}{|c|c|c|c|c|}
\hline $\begin{array}{l}\text { Ingredientes } \\
\text { Ingredients }\end{array}$ & $\begin{array}{l}\text { Alto amido c/ feno } \\
\text { de alfafa AAFA }{ }^{1} \\
\text { High starch, } \\
\text { alfalfa hay }\end{array}$ & $\begin{array}{c}\text { Alto amido c/ casca } \\
\text { de soja AACS }{ }^{2} \\
\text { High starch, } \\
\text { soybean hulls }\end{array}$ & $\begin{array}{c}\text { Baixo amido c/ feno } \\
\text { de alfafa BAFA }{ }^{3} \\
\text { Low starch, } \\
\text { alfalfa hay }\end{array}$ & $\begin{array}{c}\text { Baixo amido c/ casca } \\
\text { de soja BACS } \\
\text { Low starch, } \\
\text { soybean hulls }\end{array}$ \\
\hline Milho grão moído & 46,0 & 47,5 & 28,0 & 30,0 \\
\hline $\begin{array}{l}\text { Ground corn grain } \\
\text { Feno de alfafa } \\
\text { Alfalfa hay }\end{array}$ & 20,0 & - & 35,0 & - \\
\hline $\begin{array}{l}\text { Casca de soja } \\
\text { Soybean hulls }\end{array}$ & - & 15,0 & - & 25,0 \\
\hline $\begin{array}{l}\text { Óleo de soja } \\
\text { Soybean oil }\end{array}$ & - & - & 4,60 & 5,00 \\
\hline $\begin{array}{l}\text { Farelo de soja } \\
\text { Soybean meal }\end{array}$ & 16,0 & 20,0 & 13,5 & 20,7 \\
\hline $\begin{array}{l}\text { Farelo de trigo } \\
\text { Wheat bran }\end{array}$ & 9,00 & 9,00 & 9,00 & 9,00 \\
\hline $\begin{array}{l}\text { Sabugo milho } \\
\text { Ground corn cob }\end{array}$ & 6,00 & 5,00 & 6,00 & 5,00 \\
\hline $\begin{array}{l}\text { Sal comum } \\
\text { Salt }\end{array}$ & 0,60 & 0,60 & 0,60 & 0,60 \\
\hline $\begin{array}{l}\text { Calcário } \\
\text { Limestone }\end{array}$ & 0,60 & 1,10 & 0,05 & 0,85 \\
\hline $\begin{array}{l}\text { Fosfato bicálcico } \\
\text { Dicalcium phosphate }\end{array}$ & 1,00 & 0,90 & 1,20 & 1,10 \\
\hline $\begin{array}{l}\text { Suplem. Min. Vit. }{ }^{1} \\
\text { Mineral and vitamin premix }\end{array}$ & 0,40 & 0,40 & 0,40 & 0,40 \\
\hline $\begin{array}{l}\text { DL-metionina } \\
\text { DL-methionine }\end{array}$ & 0,05 & 0,05 & 0,10 & 0,10 \\
\hline $\begin{array}{l}\text { L-lisina } \\
\text { L-lysine }\end{array}$ & 0,10 & 0,04 & 0,09 & 0,02 \\
\hline $\begin{array}{l}\text { Caulim } \\
\text { Caulin }\end{array}$ & 0,25 & 0,41 & 1,46 & 2,23 \\
\hline Total (kg) & 100 & 100 & 100 & 100 \\
\hline
\end{tabular}

fornecida a cada animal, diariamente, correspondeu a $80 \%$ do consumo determinado por dia, durante a fase de adaptação, sendo fornecido uma vez ao dia no período da manhã $(8 \mathrm{~h})$; a água foi fornecida à vontade. A metodologia utilizada foi a de coleta total de fezes, sendo diariamente, coletadas de cada animal no período da manhã. Após a coleta, as fezes foram pesadas e acondicionadas em sacos plásticos armazenados em freezer a $-10^{\circ} \mathrm{C}$. As fezes foram homogeneizadas e colocadas em estufa de ventilação forçada a $60^{\circ} \mathrm{C}$ por 48 horas, sendo que, após este período, foram moídas e acondicionadas em recipientes plásticos, devidamente identificados, para posterior análise (Carregal, 1976; Lopes, 1996; Arruda, 1997).
As amostras de alimento, das rações e das fezes foram moídas em moinho tipo Wiley, peneira de malha $1,0 \mathrm{~mm}$, e, em seguida, acondicionadas em recipientes apropriados e identificados, para as análises químicas realizadas no Laboratório de Nutrição Animal, no Departamento de Zootecnia, da Universidade Federal de Viçosa. As análises de matéria seca, matéria mineral, proteína bruta, energia bruta e extrato etéreo foram realizadas conforme metodologia e técnicas descritas pela AOAC (1990) e Silva (1990), e as análises de fibra em detergente neutro, fibra em detergente ácido e lignina, segundo a metodologia e técnicas descritas por Van Soest et al. (1991). A análise de amido foi 
Tabela 2 - Composição química das rações experimentais (base MS)

Table 2 - Chemical composition of the experimental diets (dry matter basis)

\begin{tabular}{|c|c|c|c|c|c|c|c|}
\hline $\begin{array}{l}\text { Tratamentos } \\
\text { Treatments }\end{array}$ & & & & $\begin{array}{l}\text { Alimentos } \\
\text { Foods }\end{array}$ & & & \\
\hline $\begin{array}{l}\text { Nutrientes } \\
\text { Nutrients }\end{array}$ & $\begin{array}{l}\text { Alto amido } \\
\text { feno de } \\
\text { alfafa AAFA } 1 \\
\text { High starch, } \\
\text { alfalfa hay }\end{array}$ & $\begin{array}{l}\text { Alto amido } \\
\text { casca de } \\
\text { soja AACS }{ }^{2} \\
\text { High starch, } \\
\text { soybean hulls }\end{array}$ & $\begin{array}{l}\text { Baixo amido } \\
\text { feno de } \\
\text { alfafa BAFA } \\
\text { Low starch, } \\
\text { alfalfa hay }\end{array}$ & $\begin{array}{l}\text { Baixo amido } \\
\text { casca de } \\
\text { soja BACS } \\
\text { Low starch, } \\
\text { soybean hulls }\end{array}$ & $\begin{array}{l}\text { Milho } \\
\text { grão } \\
\text { Corn } \\
\text { grain }\end{array}$ & $\begin{array}{c}\text { Feno de } \\
\text { alfafa } \\
\text { Alfalfa } \\
\text { hay }\end{array}$ & $\begin{array}{l}\text { Casca de } \\
\text { soja } \\
\text { Soybean } \\
\text { hulls }\end{array}$ \\
\hline $\begin{array}{l}\text { Amido\% } \\
\text { Starch }\end{array}$ & 31,90 & 32,80 & 21,60 & 22,70 & 61,50 & 5,00 & 6,50 \\
\hline $\begin{array}{l}\mathrm{FDN} \% \\
N D F\end{array}$ & 24,50 & 23,20 & 30,30 & 28,90 & 8,50 & 49,00 & 61,00 \\
\hline $\begin{array}{l}\text { FDA } \% \\
A D F\end{array}$ & 14,00 & 14,40 & 18,20 & 18,70 & 3,00 & 34,00 & 41,00 \\
\hline $\begin{array}{l}\text { Lignina \% } \\
\text { Lignin }\end{array}$ & 4,00 & 2,80 & 5,90 & 3,70 & - & 12,10 & 8,90 \\
\hline $\begin{array}{l}\mathrm{EE} \% \\
\text { Ether extract }\end{array}$ & 3,10 & 2,90 & 7,40 & 7,40 & 4,20 & 3,50 & 2,90 \\
\hline $\begin{array}{l}\text { EB kcal } / \mathrm{kg} \\
\text { Gross energy }\end{array}$ & 4415 & 4281 & 4708 & 4597 & - & - & - \\
\hline $\begin{array}{l}\mathrm{ED}^{1} \mathrm{kcal} / \mathrm{kg} \\
\text { Digestible energy }\end{array}$ & 2723 & 2764 & 2583 & 2627 & - & - & - \\
\hline $\begin{array}{l}\mathrm{ED}^{2} \mathrm{kcal} / \mathrm{kg} \\
\text { Digestible energy }\end{array}$ & 2804 & 2798 & 2802 & 2799 & 3264 & 2160 & 1855 \\
\hline $\begin{array}{l}\mathrm{PB} \% \\
\text { Crude protein }\end{array}$ & 17,10 & 17,10 & 17,10 & 17,10 & 9,00 & 18,00 & 13,00 \\
\hline $\begin{array}{l}\mathrm{PD} 1 \% \\
\text { Digestible protein }\end{array}$ & 12,10 & 12,40 & 10,90 & 11,30 & - & - & - \\
\hline $\begin{array}{l}\mathrm{Ca} \% \\
\mathrm{P} \text { total } \%\end{array}$ & $\begin{array}{l}0,80 \\
0,50\end{array}$ & $\begin{array}{l}0,80 \\
0,50\end{array}$ & $\begin{array}{l}0,80 \\
0,50\end{array}$ & $\begin{array}{l}0,80 \\
0,50\end{array}$ & $\begin{array}{l}0,09 \\
0,20\end{array}$ & $\begin{array}{l}1,10 \\
0,60\end{array}$ & $\begin{array}{l}0,40 \\
0,35\end{array}$ \\
\hline $\begin{array}{l}\text { Total phosphorus } \\
\text { Lis } \% 2\end{array}$ & 0,90 & 0,90 & 0,90 & 0,90 & 0,25 & 0,95 & - \\
\hline $\begin{array}{l}\text { Lysine } \\
\text { Met } \% 2 \\
\text { Methionine }\end{array}$ & 0,60 & 0,60 & 0,60 & 0,60 & 0,19 & 0,45 & - \\
\hline
\end{tabular}

1 Determinado a partir dos coeficientes de digestibilidade (Determined from digestibility coefficients).

2 Calculado a partir dos valores nutricionais dos alimentos para coelhos obtidos pelo INRA (1984)

${ }^{2}$ Calculated from the food nutritional values to rabbits obtained by INRA (1984).

realizada pela técnica da hidrólise enzimática, conforme Ferreira et al. (1996).

Os coeficientes de digestibilidade aparente foram submetidos à análise de variância e teste de médias, a $5 \%$ de significância (Student Newman Keuls) contidos no programa SAEG - Sistema de Análises Estatísticas e Genéticas (UFV, 1997). O modelo estatístico para avaliação da digestibilidade aparente foi :

$$
Y i j k=m+A i+F j+A F i j+e i j k
$$

em que: $Y i j k l=$ valor observado das variáveis estudadas, relativo a cada unidade experimental 1 , que recebeu a ração com nível de amido i e fonte de fibra $\mathrm{j} ; \mathrm{m}=$ média geral da característica; $\mathrm{Ai}=$ efeito do nível de amido $(\mathrm{i}=1$ e 2$) ; \mathrm{Fj}=$ efeito da fonte de fibra ( $\mathrm{j}=1$ e 2 ); AFij = efeito da interação nível de amido i e fonte de fibra $\mathrm{j}$; Eijkl = erro aleatório associado a cada observação.

\section{Resultados e Discussão}

Os valores médios dos coeficientes de digestibilidade aparente dos nutrientes com coelhos na fase de crescimento, alimentados com rações contendo diferentes níveis de amido e fontes de fibra, são apresentados na Tabela 3. Pela análise de variância, não houve interação significativa entre nível de amido e fonte de fibra sobre os parâmetros avaliados $(\mathrm{P}<0,05)$, assim, os dados foram agrupados em médias para os fatores nível de amido e fonte de 
fibra isoladamente (Pimentel Gomes, 1987).

Os coeficientes de digestibilidade aparente da matéria seca (MS) e da matéria orgânica (MO) foram significativos para cada um dos fatores dietéticos em estudo $(\mathrm{P}<0,05)$. Pelos resultados da Tabela 3, constata-se que houve melhor aproveitamento dos nutrientes pelos coelhos alimentados com as rações contendo alto amido (AA), cujos valores médios de digestibilidade foram $73,56 \% \mathrm{MS}$ e $74,30 \%$ MO, e melhor aproveitamento dos nutrientes pelos coelhos alimentados com as rações contendo casca de soja (CS), cujos valores médios de digestibilidade foram $72,37 \% \mathrm{MS}$ e $73,06 \% \mathrm{MO}$.

Estas observações estão de acordo com as obti- das por Arruda et al. (2000), que verificaram melhores coeficientes de digestibilidade da matéria seca e da matéria orgânica com rações que continham maiores níveis de amido de milho, devido à maior participação dietética de carboidrato altamente digestível. Tal efeito também foi observado por Blas et al. (1990), Gidenne et al. (1990) e Parigi-Bini et al. (1990), os quais relataram que, ao se incluírem elevadas quantidades de cereais em rações para coelhos, a alta digestibilidade do amido pode promover efeito direto sobre a digestão total dos nutrientes, ao fornecer uma fração significativa de matéria seca e matéria orgânica de melhor digestibilidade.

Por outro lado, o efeito da fonte de fibra sobre a

Tabela 3 - Coeficientes de digestibilidade aparente dos nutrientes (CDAp) determinados com coelhos em fase de crescimento

Table 3 - Nutrients apparent digestibility coefficients determined with growing rabbits

\begin{tabular}{|c|c|c|c|c|c|c|}
\hline \multirow[t]{3}{*}{$\begin{array}{l}\text { Tratamentos } \\
\text { Treatments }\end{array}$} & \multicolumn{4}{|c|}{$\begin{array}{l}\text { Parâmetros } \\
\text { Parameters }\end{array}$} & \multirow{3}{*}{$\begin{array}{l}\text { Médias } \\
\text { Means }\end{array}$} & \multirow{3}{*}{$\begin{array}{l}\mathrm{CV} \\
(\%) \\
\end{array}$} \\
\hline & \multicolumn{2}{|c|}{$\begin{array}{l}\text { Níveis de amido } \\
\text { Starch levels }\end{array}$} & \multicolumn{2}{|c|}{$\begin{array}{l}\text { Fontes de fibra } \\
\text { Fiber sources }\end{array}$} & & \\
\hline & AA 1,2 & BA $^{3,4}$ & FA 1,3 & $\mathrm{CS}^{2,4}$ & & \\
\hline CDAp MS (\%) & $73,56^{\mathrm{a}}$ & $67,78^{\mathrm{b}}$ & $68,98^{f}$ & $72,37^{\mathrm{e}}$ & 70,67 & 2,90 \\
\hline $\begin{array}{l}\text { Dry matter digestibility } \\
\text { CDAp MO }(\%)\end{array}$ & $74,30^{\mathrm{a}}$ & $68,11^{\mathrm{b}}$ & $69,35^{f}$ & $73,06^{\mathrm{e}}$ & 71,21 & 2,77 \\
\hline $\begin{array}{l}\text { Organic matter digestibility } \\
\text { CDAp PB }(\%) \\
\text { Crude protein digestibility }\end{array}$ & $71,51^{\mathrm{a}}$ & $64,77^{b}$ & $67,18^{f}$ & $69,10^{\mathrm{e}}$ & 68,14 & 6,55 \\
\hline $\begin{array}{l}\text { CDAp EB }(\%) \\
\text { Gross energy digestibility }\end{array}$ & $63,89^{\mathrm{a}}$ & $56,91^{b}$ & $59,07^{f}$ & $61,74^{\mathrm{e}}$ & 60,41 & 7,23 \\
\hline $\begin{array}{l}\text { CDAp EE }(\%) \\
\text { Ether extract digestibility }\end{array}$ & $71,58^{b}$ & $79,28^{a}$ & $74,01^{f}$ & $76,84^{\mathrm{e}}$ & 75,43 & 4,63 \\
\hline $\begin{array}{l}\text { CDAp amido }(\%) \\
\text { Starch digestibility }\end{array}$ & $95,08^{a}$ & $93,81^{b}$ & $93,79^{f}$ & $95,10^{\mathrm{e}}$ & 94,45 & 1,92 \\
\hline $\begin{array}{l}\text { CDAp FDN }(\%) \\
\text { NDF digestibility }\end{array}$ & $45,87^{\mathrm{a}}$ & $41,83^{b}$ & $40,70^{f}$ & $47,00^{\mathrm{e}}$ & 43,85 & 7,81 \\
\hline $\begin{array}{l}\text { CDAp FDA }(\%) \\
\text { ADF digestibility }\end{array}$ & $37,78^{\mathrm{a}}$ & $31,34^{\mathrm{b}}$ & $30,71^{\mathrm{f}}$ & $38,42^{\mathrm{e}}$ & 34,56 & 9,50 \\
\hline $\begin{array}{l}\text { CDAp Hemicelulose }(\%) \\
\text { Hemicelullose digestibility }\end{array}$ & $55,57^{\mathrm{a}}$ & $50,65^{\mathrm{b}}$ & $50,71^{\mathrm{f}}$ & $55,51^{\mathrm{e}}$ & 53,11 & 7,22 \\
\hline $\begin{array}{l}\text { CDAp Celulose }(\%) \\
\text { Cellulose digestibility }\end{array}$ & $39,86^{\mathrm{a}}$ & $35,52^{\mathrm{b}}$ & $32,96^{\mathrm{f}}$ & $42,42^{\mathrm{e}}$ & 37,69 & 10,1 \\
\hline $\begin{array}{l}\text { Proteína digestível }{ }^{6}(\%) \\
\text { Digestible protein }\end{array}$ & $12,22^{\mathrm{a}}$ & $11,08^{b}$ & $11,48^{\mathrm{e}}$ & $11,81^{\mathrm{e}}$ & 11,65 & 6,54 \\
\hline $\begin{array}{l}\text { Energia digestível }{ }^{6}(\mathrm{kcal} / \mathrm{kg}) \\
\text { Digestible energy }\end{array}$ & $2744^{\mathrm{a}}$ & $2605^{b}$ & $2653^{\mathrm{e}}$ & $2696^{\mathrm{e}}$ & 2674 & 7,17 \\
\hline $\begin{array}{l}\text { Relação kcal ED/g PD } \\
\text { Digestible energy/protein ratio }\end{array}$ & $22,47^{\mathrm{b}}$ & $23,52^{\mathrm{a}}$ & $23,17^{\mathrm{e}}$ & $22,84^{\mathrm{e}}$ & 23,00 & 6,46 \\
\hline
\end{tabular}

a,b Médias seguidas de mesma letra não diferem pelo teste SNK $(\mathrm{P}<0,05)$ para fator nível de amido (means followed by the same letter do not differ by SNK test $(P<.05)$ for starch level factor).

e,f Médias seguidas de mesma letra não diferem $(\mathrm{P}<0,05)$ para fator fonte de fibra (means followed by same letter do not differ to each other for the test SNK $(P<.05)$ for fiber font factor).

1,2,3,4 Rações experimentais (vide Tabelas 1 e 2) (Experimental diets [see Tables 1 and 2]).

5 Interação não-significativa (non significant interaction).

6 Determinado a partir dos resultados do ensaio de digestibilidade (determined from results of digestibility assay).

R. Bras. Zootec., v.31, n.3, p.1166-1175, 2002 
digestibilidade da matéria seca e da matéria orgânica correlaciona-se diretamente com as características da parede celular do alimento fibroso (Merino \& Carabaño, 1992; Cheeke, 1995; De Blas \& Wiseman, 1998). O feno de alfafa, apesar de ser a fonte de fibra referência na alimentação de coelhos, possui qualidades nutricionais que extrapolam a contribuição da parede celular, porém, sugere-se, no caso da fibra, que a casca de soja, por ser um alimento menos lignificado, proporcionou maiores tempo de retenção e disponibilidade de nutrientes, assim como melhor degradação da fração fibrosa pela atividade microbiana cecal, contribuindo para melhor digestibilidade destas rações (Gidenne, 1992; Gidenne \& Jehl, 1996; Garcia et al., 1997).

Os coeficientes de digestibilidade aparente da proteína bruta foram significativos apenas para nível de amido $(\mathrm{P}<0,05)$, enquanto a fonte de fibra não proporcionou efeito significativo para este parâmetro. Observando-se os resultados na Tabela 3, verifica-se melhor digestibilidade da fração protéica pelos coelhos alimentados com as rações contendo alto amido (AA - 71,51\%) em relação às de baixo amido (BA $64,77 \%$ ), sendo tal resposta possivelmente decorrente da redução do tempo de retenção da digesta com as rações mais fibrosas (Blas et al., 1990; Merino \& Carabaño, 1992; Gidenne, 1992), proporcionando melhor aproveitamento da fração protéica e aminoacídica pelos coelhos. Apesar de não ter sido constatado efeito significativo entre as diferentes fontes de fibra, em termos absolutos, observou-se ligeira superioridade na digestibilidade da fração protéica com as rações contendo casca de soja (CS), possivelmente, em virtude do balanceamento isoprotéico, havendo necessidade de maior inclusão de farelo de soja nestas rações (Tabela 1), fato determinante para tal observação. Porém, vale destacar a notável eficiência dos coelhos em aproveitar a fração protéica da alfafa pela ausência de diferenças estatísticas para fonte de fibra.

Os coeficientes de digestibilidade aparente da energia bruta foram significativos $(\mathrm{P}<0,05)$ tanto para nível de amido quanto para fonte de fibra, mas não para a interação entre eles. Na Tabela 3, verifica-se melhor aproveitamento da energia pelos coelhos alimentados com as rações contendo alto amido (AA), com digestibilidade média de $63,89 \%$, e houve também melhor aproveitamento da energia pelos coelhos alimentados com as rações contendo casca de soja (CS), com digestibilidade média de 61,74\%.
Neste estudo, os tratamentos dietéticos tiveram relação inversa entre nível de amido e de fibra, assim, constatou-se que a redução do nível de amido promoveu menor eficiência no aproveitamento da energia dietética, apesar da inclusão de óleo de soja para torná-las isoenergéticas. As rações com os maiores níveis de amido propiciaram maior aporte energético aos coelhos, possivelmente, devido à taxa de passagem das frações digestíveis (Lleonart, 1980; De Blas, 1991). Por outro lado, ao se analisar o efeito do alimento volumoso, a fonte de fibra também influenciou o aproveitamento da energia da dieta pelos coelhos, já que as rações contendo casca de soja (CS) propiciaram melhores valores de digestibilidade, devido ao menor efeito da lignificação da parede celular (Lang, 1981; Lebas, 1991; Santomá et al., 1993).

Assim, quantidade e qualidade da fibra dietética são importantes nutricionalmente para coelhos, não só pelo fornecimento de energia pela atividade fermentativa cecal, mas principalmente pelos efeitos sobre a viscosidade e regulação do trânsito da digesta, determinantes para digestibilidade dos nutrientes e normalidade da fisiologia digestiva nesta espécie (Morisse, 1982; Cheeke, 1987; De Blas, 1989; Gidenne, 1992). Adicionalmente, a redução do nível de fibra subentende maior quantidade de nutrientes a serem digeridos e absorvidos, promovendo melhores níveis de energia digestível nas rações (Lopes, 1996), e fontes de fibra de baixa lignificação tendem a maximizar a digestão endógena e microbiana (Gomes, 1996).

Os coeficientes de digestibilidade aparente do extrato etéreo foram significativos $(\mathrm{P}<0,05)$ tanto para nível de amido quanto para fonte de fibra, mas não para a interação entre eles. Na Tabela 3, verifica-se melhor digestibilidade da fração lipídica pelos coelhos alimentados com as rações contendo menores níveis de amido (AA - 79,28\%), e, melhor digestibilidade da fração lipídica pelos coelhos alimentados com as rações contendo casca de soja (CS - 76,84\%).

Segundo Lleonart (1980) e Church (1988), a maior presença de lipídios na digesta aumenta a secreção de sais biliares e das lipases pancreáticas, e a reabsorção de bíle e sua elevação na circulação enterohepática também estimulariam a digestão deste nutriente. Além desta sustentação fisiológica, as rações com menores níveis de amido (BA) também continham maiores níveis de inclusão de óleo de soja para efetivar a equivalência da energia dietética

\section{R. Bras. Zootec., v.31, n.3, p.1166-1175, 2002}


entre os tratamentos (Tabela 1), diferencial que se traduz na disponibilidade dos lipídios intracelulares nos alimentos. Os resultados obtidos foram similares aos de Arruda et al. (2000), os quais verificaram que a suplementação com óleo de soja em rações isofibrosas foi responsável pela maior digestibilidade do extrato etéreo, em concordância com Maertens et al. (1992) e Fernandez et al. (1994), que verificaram alta digestibilidade para o óleo de soja, e Cheeke (1989), para eficiência no aproveitamento dos lipídios em níveis inferiores a $10 \%$ na dieta.

Comparando-se a digestibilidade do extrato etéreo das rações contendo diferentes fontes de fibra, os menores valores obtidos com as rações contendo feno de alfafa (FA) devem-se ao efeito sobre a motilidade intestinal, em função da natureza da fibra, pois a maior velocidade de passagem pode ter contribuído para a menor digestibilidade, já que esta se processa mais lentamente em relação aos outros nutrientes (Swenson \& Reece, 1996; De Blas \& Wiseman, 1998). Além disso, alterações na viscosidade intestinal causadas pelas pentosanas, pectinas e lignocelulose presentes na fibra podem influenciar a negativamente a digestibilidade da dieta, relacionados à peristalse, adsorção de lipídios da digesta, processo de emulsificação, hidrólise e esterificação para absorção intestinal (Penz JR., 1998; Fernandez et al., 1994).

Com relação à digestibilidade aparente do amido, verificou-se efeito significativo $(\mathrm{P}<0,05)$ para nível de amido e para fonte de fibra, mas não para a interação. Observando-se os resultados na Tabela 3, constatou-se que a melhor digestibilidade da fração amilácea pelos coelhos alimentados com as rações contendo alto amido (AA - 95,08\%) sugere alta atividade amilásica nos coelhos e capaz de digerir as quantidades de amido incorporadas às rações (Gidenne \& Perez, 1993a,b; Marounek et al., 1995). Já o melhor aproveitamento do amido dietético pelos coelhos alimentados com as rações contendo casca de soja (CS - 95,10\%) sugere possível influência da composição química da parede celular sobre a digestibilidade do amido (Cheeke, 1995).

Segundo Lleonart (1980) e Church (1988), a quantidade e composição da digesta que chega ao intestino são determinantes para o volume e composição das secreções pancreáticas, assim, a quantidade de amido dietético influencia a quantidade de alfaamilase e sacaridases nas microvilosidades intestinais (Blas et al., 1990), caracterizando a atividade e secreção enzimática como substrato-dependente, o que permite sustentação fisiológica para justificar os resultados obtidos. Por outro lado, Cheeke (1995), De Blas \& Wiseman (1998) relataram que a fração fibrosa pode promover maior peristalse e reduzir a eficiência digestiva, além de a higroscopicidade da fibra aumentar a viscosidade da digesta e reduzir a digestibilidade dos nutrientes, em concordância com Bedford \& Classen (1992) e Penz Jr. (1998), que sustentam estes efeitos, conferidos pelos betaglucanos e arabinoxilanos, em diferentes magnitudes, na alteração da digestibilidade dos nutrientes, visto que podem dificultar a ação das enzimas e a difusão de substâncias relacionadas com o processo digestivo.

Considerando que a propriedade físico-química do amido dietético possui papel determinante sobre a extensão de sua digestibilidade (Greenwood, 1970), vale destacar que os valores obtidos neste estudo foram muito bons, sendo superiores a $90 \%$ em todos os tratamentos (Tabela 3). No entanto, fatores intrínsecos aos alimentos podem justificar as pequenas, mas significativas, diferenças observadas neste estudo, como, por exemplo, a encapsulação celular do endosperma, processo de moagem, resistência propiciada pelo conteúdo de água entre os polímeros de glicose, forma de distribuição da amilose no grão de milho, menor penetração de água e exposição do sítio de hidrólise da forma vítrea da amilose em relação à forma amorfa da amilopectina, a gelatinização do amido e sua posterior agregação com a parede celular e proteínas, além da reação de Maillard promovida pelo excesso de calor na peletização das rações, entre outros, que concorrem para diferenças na digestibilidade total da fração amilácea das rações (Lee et al., 1985; Rooney \& Pflugfelder, 1986; Gidenne \& Perez, 1993 a,b; Penz Jr., 1998; Arruda et al., 2000).

Os coeficientes de digestibilidade aparente da fibra em detergente neutro (FDN) e fibra em detergente ácido (FDA) foram significativos $(\mathrm{P}<0,05)$ tanto para nível de amido quanto para fonte de fibra, mas não para a interação entre eles. Os resultados são apresentados na Tabela 3, na qual se constata melhor digestibilidade da fração fibrosa pelos coelhos alimentados com as rações contendo maiores níveis de amido (AA) com valores médios de $45,87 \%$ para FDN e 37,78\% para FDA, e melhor digestibilidade da fração fibrosa pelos coelhos alimentados com as rações contendo casca de soja (CS), com valores médios de 47,00\%para FDN e 38,42\% para FDA.

\section{R. Bras. Zootec., v.31, n.3, p.1166-1175, 2002}


Segundo Gidenne \& Perez (1993 a,b) e Arruda et al. (2000), a digestibilidade da fibra (FDN e FDA) pode ser otimizada com a elevação dos níveis de amido dietético, devido ao aporte adequado de energia suplementar fornecido por um substrato mais equilibrado qualitativamente, melhorando a degradabilidade da fração fibrosa ao aumentar a atividade fermentativa. Além disso, as rações com menores níveis de amido (BA) estavam associadas à suplementação com óleo de soja, e a passagem de certa quantidade indigerida ao ceco pode ter sido suficiente para reduzir a atividade fermentativa, possivelmente pelo envolvimento das partículas fibrosas por uma camada oleosa, dificultando a aderência dos microorganismos cecais e digestão, além de possível efeito deletério sobre as membranas bacterianas (Palmquist etal.,1986; Van Soest, 1994; Gidenne, 1995).

Com relação às fontes de fibra, a natureza da parede celular vegetal é determinante sobre a eficiência de degradação microbiana cecal (Merino \& Carabaño, 1992; Garcia et al., 1993; Gidenne, 1994; Ferreira et al., 1996), visto que as rações com casca de soja (CS) propiciaram material menos lignificado e, possivelmente, maior tempo de retenção para atividade fermentativa, aliado a maior efeito antiperistáltico, contribuindo para melhor colonização e ação enzimática da microflora do ceco - cólon sobre a fração fibrosa, o que justificaria a melhor digestibilidade de FDN e FDA destas rações (Perez de Ayala et al., 1991; De Blas \& Wiseman, 1998).

Os coeficientes de digestibilidade aparente da hemicelulose e celulose foram significativos $(\mathrm{P}<0,05)$ tanto para nível de amido quanto para fonte de fibra, mas não para interação entre eles. Na Tabela 3, pode-se constatar melhor digestibilidade da hemicelulose e celulose com as rações contendo maiores níveis de amido (AA), cujos valores médios foram 55,57 e $39,86 \%$, respectivamente, e melhor digestibilidade da hemicelulose e celulose com as rações contendo casca de soja (CS), cujos valores médios foram 55,51 e $42,42 \%$, respectivamente.

A celulose caracteriza-se como homopolímero de cadeia linear d-glicopiranosil unidas por ligações beta-1,4 agregadas em microfibrilas estruturais da parede primária e secundária dos vegetais. A hemicelulose caracteriza-se como um heteropolímero unido por um grau de polimerização menor que a da celulose, contendo xiloglucanos e arabinoxilanos, além de polissacarídeos unidos por ligações alfa e beta-1,3, beta-1,6, alfa-1,4, tal como arabinogalactanos, galactomananos e glucomananos. A lignina é formada por três unidades fenilpropano (ácidos coniferílico, coumarílico e sinapílico), responsáveis pela fixação, rigidez e resistência da parede celular vegetal (Van Soest, 1994; Brett \& Waldron, 1996). Assim, as rações que continham casca de soja (CS) como volumoso predominante, devido aos menores teores de lignina, propiciaram os melhores valores de digestibilidade para hemicelulose e celulose, assim como para frações FDN e FDA observadas anteriormente, pois a lignina pode prejudicar a atividade celulolítica microbiana. Já os valores de digestibilidade superiores para rações de alto amido (AA) podem ser fundamentados na sincronização energia e proteína para a microflora cecal, proporcionalmente, pelo maior aporte de amido indigerido que alcançou este compartimento digestivo, maximizando a atividade fermentativa cecal dos coelhos (Gidenne \& Perez, 1993a,b; Carabaño, 2000).

Existem evidências de que parte da fibra dietética possa ser digerida antes de chegar ao ceco dos coelhos, e a extensão da degradação pré-cecal é altamente variável, cuja amplitude para fração FDN varia de 5 a $40 \%$, conforme o volumoso (Gidenne \& Ruckebush, 1989; Merino \& Carabaño, 1992). Segundo Gidenne (1992), substâncias pécticas como arabinose e ácidos urônicos são efetivamente digeridas quando a digesta chega ao íleo terminal, pois há presença de hidrocarbonases no estômago e intestino delgado, especialmente pectinases e xilanases (Marounek et al., 1995). Ao associar-se tal efeito com a natureza da parede celular do volumoso na dieta, podem-se justificar os maiores coeficientes de digestibilidade da hemicelulose em relação aos da celulose em coelhos (Falcão \& Cunha et al., 1996). Adicionalmente, a atividade microbiana cecal dos coelhos é capaz de degradar pectinas e hemicelulose com maior eficiência que a celulose, devido à menor proporção da microflora celulolítica comparada à xilanolítica ou pectinolítica, o que se deve ao mecanismo fisiológico de separação de partículas entre o ceco e o cólon para atividade fermentativa e o processo de cecotrofia, associado ao fato de os coelhos possuírem a digestão enzimática endógena anterior à digestão microbiana simbiótica (Gidenne, 1996; Gidenne \& Jehl, 1996; De Blas \& Wiseman, 1998).

Finalmente, com base nos coeficientes de digestibilidade obtidos para a fração energética e protéica, pode-se obter a quantidade de energia e proteína digestíveis das rações experimentais e esta-

\section{R. Bras. Zootec., v.31, n.3, p.1166-1175, 2002}


belecer uma relação entre elas que possui alta correlação com a eficiência alimentar, desempenho produtivo e prevenção de distúrbios digestivos. Segundo De Blas (1989) e De Blas \& Wiseman (1998), uma relação ótima seria em torno de $23 \mathrm{kcal}$ de energia digestível por grama de proteína digestível, o que permite constatar que todas as rações experimentais formuladas para este estudo (Tabela 2) se aproximaram desta relação, porém, na Tabela 3 , seguindo a linha de raciocínio estabelecida pela ausência de interação significativa entre os tratamentos, verificase que as rações contendo maiores níveis de amido (AA) e as rações contendo casca de soja (CS) se aproximaram do valor preconizado, sugerindo que a casca de soja pode ser utilizada eficientemente pelos coelhos, assim como altos níveis de amido, porém, respeitando-se os limites impostos pelas recomendações nutricionais.

\section{Conclusões}

Com base nos resultados obtidos neste estudo, pode-se concluir que as rações contendo maiores níveis de amido e aquelas contendo casca de soja foram as que proporcionaram melhores coeficientes de digestibilidade aparente dos nutrientes e, conseqüentemente, excelente relação energia/proteína digestíveis para coelhos em crescimento.

\section{Agradecimento}

À Santista Alimentos SA - Divisão SAMRIG, pela doação da casca de soja usada neste estudo.

\section{Literatura Citada}

ASSOCIATION OF OFFICIAL ANALYTICAL CHEMISTS AOAC. Official methods of analysis. 15.ed. Arlington: 1990, 1117p.

ARRUDA, A.M.V. Digestibilidade, desempenho e produção de ácidos graxos voláteis de coelhos alimentados com rações contendo diferentes níveis de amido. Jaboticabal: Universidade Estadual Paulista, 1997. 96p. Dissertação (Mestrado em Zootecnia) - Universidade Estadual Paulista, 1997.

ARRUDA, A.M.V.; CARREGAL, R.D.; FERREIRA, R.G. Digestibilidade aparente de rações contendo diferentes níveis de amido para coelhos em crescimento. Revista Brasileira Zootecnia, v.29, n.3, p.769-775, 2000.

BEDFORD, M.R.; CLASSEN, H.L. Reduction of intestinal viscosity through manipulation of dietary rye and pentosanase concentration is affected through changes in the carbohydrate composition of the intestinal aqueous phase and results improved growth rate and feed convertion efficiency in broiler chicks. Journal of Nutrition, v.122, p.560-569, 1992.

BLAS, E.; FANDOS, J.C.; CERVERA, C. et al. Effet de la nature et du taux d'amidon sur l'utilisation digestive de la ration chez le lapin au cours de la croissance. Paris: 1990. 10p.

BRETT, C.T.; WALDRON, K.W. Physiology and biochemistry of plant cell walls. 2.ed. Cambrigde University Press: $C \& H$ Books, 1996. 255p.

CARABAÑO, R.M. Sistemas de producción de conejos en condiciones intensivas. In: REUNIÃO ANUAL DA SOCIEDADE BRASILEIRA DE ZOOTECNIA, 37., 2000, Viçosa, MG. Anais...Viçosa, MG: Sociedade Brasileira de Zootecnia, 2000. p.17-38.

CARREGAL, R.D. Efeito da idade e de diferentes níveis de fibra bruta sobre a digestibilidade de nutrientes de rações de coelhos. Piracicaba: Escola Superior de Agricultura "Luiz de Queiroz", 1976. 70p. Dissertação (Mestrado em Zootecnia) - Escola Superior de Agricultura "Luiz de Queiroz", 1976.

CHEEKE, P.R.; PATTON, N.M. Carbohydrate-overload of the hindgut: a probable cause of enteritis. Journal of Applied Rabbit Research, v.3, n.1, p.20-23, 1980.

CHEEKE, P.R. Rabbit feeding and nutrition. Oregon: Academic Press, 1987. 380p.

CHEEKE, P.R.; PATTON, N.M.; LUKEFAHR, S.D. et al. Rabbit production. Illinois: The Interstate Printers and Publishers, 1989. 472p.

CHEEKE, P.R. Alimentación y nutrición del conejo. Zaragoza: Acribia, 1995. 429p.

CHURCH, D.C. The ruminant animal digestive physiology and nutrition. New Jersey: Prentice Hall, 1998. 562p.

DE BLAS, C. Alimentación del conejo. Madrid: Ed. MundiPrensa, 1989. 175p.

DE BLAS, C. Alimentazione in svezzamento i patologia digestiva. Rivista di Coniglicoltura, v.28, n.7, p.13-21, 1991.

DE BLAS, C.; WISEMAN, J. The nutrition of the rabbit. Cambrigde: University Press - CAB International, 1998. 344p.

FALCÃO e CUNHA, L.; BENGALA-FREIRE, J.P.; GONÇALVES, A. Effect of fat level and fiber nature on performance, digestibility, nitrogen balance and digestive organs in growing rabbits. In: WORLD RABBIT CONGRESS, 6., 1996, Tolouse. Proceedings... Tolouse: AFC - INRA, 1996. v.1. p.157-164.

FERNANDEZ, C.; COBOS, A.; FRAGA, M.J. The effect of fat inclusion on diet digestibility in growing rabbits. Journal of Animal Science, v.72, p.1508-1515, 1994.

FERREIRA, W.M. Matérias-primas utilizadas na formulação de rações para coelhos: restrições e alternativas. Informe Agropecuário, v.14, n.159, p.16-24, 1989.

FERREIRA, W.M.; FRAGA, M.J.; CARABAÑO, R. Inclusion of grape pomace in substitution for alfalfa hay in diets for growing rabbits. Animal Science, v.63, n.1, p.167-174, 1996.

GARCIA, G.; GALVEZ, J.F.; DE BLAS, J.C. Effect of substitution of sugar beet pulp in diets for finishing rabbits on growth performance and nitrogen efficiency. Journal of Animal Science, v.71, p.1823-1830, 1993.

GARCIA, J.; VILLAMIDE, M.J.; DE BLAS, J.C. Energy, protein and fiber digestibility of soya bean hulls for rabbits. World Rabbit Science, v.5, n.3, p.111-115, 1997.

GIDENNE, T.; RUCKEBUSH, Y. Flow and passage rate studies at the ileal level in the rabbit. Reproduction Nutrition Development, v.29, p.403-412, 1989.

GIDENNE, T.; PEREZ, J.M.; VIUDES, P. et al. Digestive efficiency in the rabbit effect of age and starch origin. Bol. Cuniculture, v.14, n.3, p.54-60, 1990.

GIDENNE, T. Effect of fiber level, particle size and adaptation period on digestibility and rate of passage as measured at the ileum and in the faeces in the adult rabbit. British Journal of

R. Bras. Zootec., v.31, n.3, p.1166-1175, 2002 
Nutrition, v.67, n.1, p.133-146, 1992.

GIDENNE, T.; PEREZ, J.M. Effect of dietary starch origin on digestion in the rabbit: digestibility measurements from weaning to slaughter. Animal Feed Science and Technology, v.42, p.237-247, 1993a.

GIDENNE, T., PEREZ, J.M. Effect of dietary starch origin on digestion in the rabbit: starch hydrolysis in the small intestine, cell wall degradation and rate of passage measurements. . Animal Feed Science and Technology, v.42, p.249-257, 1993b.

GIDENNE, T.Effets d'une réduction de la teneur en fibres alimentaires sur le transit digestif du lapin. Comparison et validation de modéles d'ajustement des cinétiques d'excrétion fécale des marqueurs. Reproduction Nutrition and Development, v.34, p.295-307, 1994.

GIDENNE, T. Apports de fibres et d'amidon: consequences digestives chez le lapin en croissance. In: JORNADA TÉCNICA SOBRE CUNICULTURA, 7., 1995, Barcelona. EXPOAVIGA'95... Barcelona, 1995. p.805-825.

GIDENNE, T. Nutritional and ontogenic factors affecting rabbit caeco-colic digestive phisiology. In: WORLD RABBIT CONGRESS, 6., 1996, Tolouse. Invited Papers...Tolouse, AFC - INRA, 1996. p.13-28.

GIDENNE, T.; JEHL, N. Replacement of starch by digestible fiber in the feed for growing rabbit: consequences for digestibility and rate of passage. Animal Feed Science and Technology, v.61, p.183-192, 1996.

GOMES, A.V.C. Utilização de diferentes fontes de fibra na alimentação de coelhos em crescimento. Belo Horizonte: Universidade Federal de Minas Gerais, 1996. 129p. Tese (Doutorado em Zootecnia) - Universidade Federal de Minas Gerais, 1996.

GREENWOOD, C.T. Starch and glycogen. In: PIGMAN, W.; HORTON, D. (Eds.) The carbohydrates. New York: Academic Press, 1970. p.471-509.

INSTITUT NATIONAL DE LA RECHERCHE AGRONOMIQUE - INRA. L'alimentation des animaux monogatriques: porc, lapin e volailles. Tolouse, Publiè du Ministère Français, 1984. p.77-84.

LANG, J. The nutrition of the commercial rabbit. Part 1 - Physiology, digestibility and nutrient requirements. Nutrition Abstracts and Reviews, Serie-B, v.51, n.4, p.197-221, 1981.

LEBAS, F.; COUDERT, P.; ROUVIER, A. et al. EI conejo: cria y patologia. Rome: Organización de las Nacioenes Unidas para la Agricultura y la Alimentación, 1986.278p. (Colecciones FAO)

LEBAS, F. Alimentación y funcionamiento digestivo del conejo. Cuniculture, v.16, n.92, p.224-228. 1991.

LEBAS, F. La alimentación practica del conejo de engorde. Boletim Cuniculture, v.1, n.59, p.34-43, 1992.

LEBAS, F. Recomendações alimentares - Alimentação dos coelhos. In : INRA - Alimentação dos animais monogástricos: suínos, coelhos e aves. 2.ed. São Paulo: Roca, 1999. p.76-84.

LEE, P.C.; BROOKS, S.P.; KIM, O. et al. Digestibility of native and modified starches: in vitro studies with human and rabbit pancreatic amylases and in vivo studies in rabbits. Journal of Nutrition, n.115, p.93-103, 1985.

LLEONART, F.R. Tratado de cunicultura. Anatomía y fisiología del aparato digestivo. Barcelona: Real Escuela Oficial y Superior de Avicultura, 1980. v.1. p.61-84.

LOPES, D.C. Avaliação de alimentos e exigência de energia digestível de coelhos da raça Nova Zelândia Branco em crescimento e reprodução. Viçosa, MG: Universidade Federal de Viçosa, 1996, 114p. Tese (Doutorado em Zootecnia) Universidade Federal de Viçosa, 1996.

MAERTENS, L. Rabbit nutrition and feeding - A review of some recent developments. Journal of Applied Rabbit Research, v.15, n.1, p.889-915, 1992.

MAROUNEK, M.; VOVK, S.J.; SKRIVANOVA, V. Distribution of activity of hidrolytic enzimes in the digestive tract of rabbits. British Journal of Nutrition, v.73, p.463-469, 1995.

MERINO, J.; CARABAÑO, R. Effect of type of fiber on ileal and fecal digestibilities. Journal of Applied Rabbit Research, v.15, p.931-937, 1992.

MORISSE, J.P. L'Alimentation du lapin: composante primordiale de l'equilebre digestif, rôle des glucides. Revisti di Alimentacion Animal, v.354, p.635-642, 1982.

MORISSE, J.P. Incidenza delle turbe digestive e delle enteropatie sulla mortalità del coniglio. Rivista di Coniglicoltura, v.23, n.2, p.28-36, 1986.

PALMQUIST, D.L.; JENKINS, T.C.; JOYNER JR., A.E. Effect of dietary fat and calcium source on insoluble soap formation in the rumen. Journal of Dairy Science, v.69, p.1020-1030, 1986.

PARIGI-BINI, R.; XICCATO, G.; CINETTO, M. Influenza del contenuto di amido alimentare sulla produtivita, sulla digeribilita e sula composizione corporea di conigli in accrescimento. Zoot. Nutrition Animal, v.16, n.1, p.271-282, 1990.

PENZ JR., A.M. Enzimas em rações para aves e suínos. In: REUNIÃO ANUAL DA SOCIEDADE BRASILEIRA DE ZOOTECNIA, 35., 1998, Botucatu. Anais... Botucatu: Sociedade Brasileira de Zootecnia, 1998. p.165-179.

PEREZ DE AYALA, P.; FRAGA, M.J.; CARABAÑO, R. et al. Effect of fiber source on diet digestibility and growth in fattening rabbits. Journal of Applied Rabbit Research, v.14, n.1, p.159-164, 1991.

PIMENTEL GOMES, F.P. Curso de estatística experimental. Piracicaba: Escola Superior de Agricultura "Luiz de Queiroz", 1987. 467p.

ROONEY, L.W.; PFLUGFELDER, R.L. Factors affecting starch digestibility with special emphasis on sorghum and corn. Journal of Animal Science, v.63, p.1607-1623, 1986.

SANTOMÁ, G.; DE BLAS, J.C.; CARABAÑO, R. et al. Nutrition of rabbits. Madrid: Cyanamid Ibérica, 1993. 57p.

SILVA, D.J. Análise de alimentos: métodos químicos e biológicos. Viçosa: Universidade Federal de Viçosa, 1990. 166p.

SWENSON, M.J.; REECE, W.O. DUKES - Fisiologia dos animais domésticos. Rio de Janeiro: Guanabara Koogan, 1996. $856 \mathrm{p}$.

UNIVERSIDADE FEDERAL DE VIÇOSA - UFV. SAEG - Sistemas de Análises Estatísticas e Genéticas. Versão 7.1. Viçosa, MG, 1997. 150p. (Manual do usuário)

Van SOEST, P.J.; ROBERTSON, J.B.; LEWIS, B.A. Methods for dietary fiber, neutral detergent fiber, and nonstarch polyssacharides in relation to animal nutrition. Journal of Dairy Science, v.74, n.10, p.3583-3597, 1991.

Van SOEST, P.J. Nutritional ecology of the ruminant. O\&B Books, 2.ed. Cornell: University Press, 1994. 476p. 